Original Article

\title{
MOLECULAR DETECTION OF RUBELLA VIRUS GLYCOPROTEIN AMONG WOMEN OF CHILDBEARING AGE IN LOKOJA
}

\author{
O M Kolawole ${ }^{1}$, M M Suleiman ${ }^{2}$, O Alabl ${ }^{3}$, I J Ogah ${ }^{4} \&$ O O Amuda ${ }^{5}$ \\ ${ }^{1}$ Senior Lecturer, ${ }^{2,4,5}$ Research Scholars, Medical Microbiology, Department of Microbiology, University of Ilorin, \\ ${ }^{3}$ Consultant Gynecologist, Federal Medical Centre, Lokoja, Nigeria \\ Correspondence : \\ Olatunji M. Kolawole \\ Infectious Diseases and Environmental Health Research Group, Department of Microbiology, Faculty of Life Sciences, \\ University of llorin, llorin Nigeria. \\ Mobile : +234-8060088495 E-mail : omk@unilorin.edu.ng \& tomak7475@gmail.com
}

\begin{abstract}
:
Background : The gene order for the Rubella virus (RV) 40S RNA is 5' -p150-p90-C-E2-E1-3' and the complete nucleotide sequence of RV has been determined for three strains. The RV core is surrounded by a host-derived lipid bilayer containing 5-6nm long spikes composed of the $\mathrm{E} 2$ and $\mathrm{E} 1$ glycoproteins
\end{abstract}

Objective(s) : Molecular detection of Rubella virus glycoprotein after serum screening of 240 women attending Federal Medical Centre Lokoja (FMC) via IgG and IgM ELISA.

Method: Cross-sectional study was carried out in Obstetrics and Gynecology clinic at FMC Lokoja. Serology for anti RV-IgG and IgM was done for 240 blood samples after serum separation. Polymerase Chain Reaction (PCR) was done for rubella cDNA via RUB $2 \& 7$ and RUB $8 \& 11$ specific primers and this was sequenced using dye terminator cycle sequencing.

Result : $231(96.25 \%)$ of 240 and 4(1.7\%) of 231 subjects were positive to Rubella IgG and IgM respectively after assay. PCR band result had $320 \mathrm{bp}$ on $1 \mathrm{~kb}$ DNA plus ladder of $0.9 \mu \mathrm{g} /$ lane and live blast of the 320 length sequence result revealed a Rubella membrane glycoprotein E1 (Rubella_E1). All subjects that had blood transfusion were positive to Rub-IgG ( $p=0.566$ ) while 3(1.6\%) of 168(88.9\%) respondents with no blood transfusion were IgM positive $(P=0.537) .61(32.6 \%)$ of $67(35.8 \%)$ respondent who reported history of rash were positive to Rub-IgG ( $p=0.057)$ and of $30(22.7 \%)$ that has had a miscarriage, $29(22.0 \%)$ was positive to $R u b-\operatorname{lgG}(p=0.731)$

Conclusion : Rubella virus membrane glycoprotein E1, an important structural type 1 membrane protein in the entire pathogenesis of rubella virus has been confirmed in this locality.

Keywords: Rubella, Parity, seroprevalence, IgM, IgG.

\section{Introduction :}

Rubella usually begins with malaise, low-grade fever, and a morbilliform rash appearing same day. The rash starts on the face, extends over the trunk and extremities, and rarely last more than 3 days. Unless an epidemic occurs, the disease is difficult to diagnose clinically, as the rash caused by other viruses (e.g.enteroviruses) ${ }^{1,2}$. It can either cross the placenta to cause Access this article online Quick Response Code

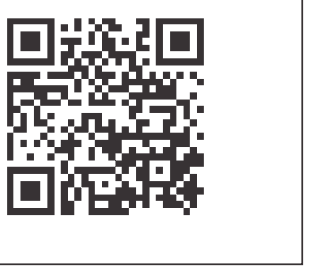
congenital infections to fetus, abortion, intrauterine death, preterm labor or infect the baby prenatally as it passes through the birth canal of the mother or in postnatal life.

It's a non-arthropod-borne Togavirus and only member of the genus Rubivirus. It's an enveloped ssRNA circular or oval shaped virus of $60 \mathrm{~nm}$ in diameter and nucleocapsid of $33 \mathrm{~nm}$ symmetry thought to be icosahedral but virus particle has a pleomorphic appearance. Rubella is a +ve $40 \mathrm{~S}$ RNA virus consisting of 3 structural proteins. The outer membrane is a host derived lipid bilayer containing specialized glycoproteins (E1: 58kDa and E2: 42-46kDa). Rubella virus matures and buds off from infected cells either at the plasma membrane or at the internal membranes depending on the cell type. It proceeds to enter adjacent uninfected cells by a membrane fusion process in the endosome and this is directed by E1-E2 heterodimers. The heterodimer formation is crucial for the 
transport of E1 out of the Endoplasmic reticulum to the Golgi and plasma membrane. The E1 has been shown to be a type 1 membrane protein that is rich in cysteine residues with extensive intramolecular disulfide bonds ${ }^{3}$.

The full-length RV genome measures 9,762 nt and contains two long open reading frames (ORFs) ${ }^{4}$. The RV 5?-proximal ORF of 6,345 nt encodes the viral ns proteins, p150 and p90, while the 3? ORF of 3,189 nt encodes the structural proteins, capsid (C), E2, and E1 an earlier report ${ }^{5}$. Thus, the gene order for the RV 40S RNA is 5? -p150-p90-C-E2-E1-3? Study by Pugachev ${ }^{6}$ reveals that the complete nucleotide sequence of RV has been determined for three strains, Therien, M33, and RA27/3. Nucleotide and deduced amino acid sequencing analysis reveals a high degree of homology between strains, ranging from 97.2 to $99 \%$ and 97.6 to $98.9 \%$ at the nucleotide and amino acid levels, respectively. The capsid protein is a non-glycosylated, phosphorylated, disulfide-linked homodimer with a reported molecular mass of 33 to $38 \mathrm{kDa}$. It contains clusters of proline and arginine residues, which have been postulated to be involved in binding to the RV genomic RNA to form the viral nucleocapsids.

The functions of the RV E1 and E2 glycoproteins have been studied extensively. Using monoclonal antibodies, it has been shown that the E1 protein contains at least six non overlapping epitopes, some of which are associated with hemagglutination and neutralization. E1 appears to be the main surface protein, with domains involved in the attachment of the virus to the cell. The 28-residue internal hydrophobic domain of E1 is responsible for the fusogenic activity of RV. In addition, this region is involved in the binding to E2 for heterodimer formation. The function of E2 has been more difficult to determine because it's less accessible to characterization by monoclonal antibodies? ${ }^{7}$.

To the best of my knowledge, molecular confirmation or detection of rubella virus glycoproteins has not been carried out or published in this locality thus; this research aims to provide scientific data on molecular detection of rubella virus type 1 membrane protein and also establish the role of blood transfusion as a route of rubella virus transmission.

\section{Materials and Methods :}

\section{Study area}

The research was carried out in Lokoja city located on $7^{\circ} 49^{\prime} \mathrm{N} 6^{\circ} 45^{\prime} \mathrm{E} / 7.817^{\circ} \mathrm{N} 6.750^{\circ} \mathrm{E}$. Lokoja is the capital of Kogi state in Nigeria North central and sample collection was carried out at Federal Medical Center Lokoja.

\section{Subjects and Sample collection}

Sample size was calculated via Fishers formula ${ }^{8}, 5 \mathrm{ml}$ of blood was aseptically drawn from 240 consenting females of childbearing age and a structured questionnaire was used to gather information on history of rash, miscarriage or pregnancy loss and history of blood transfusion among respondents. Sera was separated and stored at $-20^{\circ} \mathrm{C}$ for assay and also as biological fluid for molecular process.

\section{Assay}

This was carried out using Enzyme Linked Immunosorbent Assay method (ELISA) which has been shown to be a sensitive and reliable procedure for detection of antibodies to rubella with diagnostic sensitivity of $98 \%$ and diagnostic specificity of $\geqslant 98 \%$. The IgG seropositive cases were regarded as exposed, while the IgM seropositive cases were regarded as acute or active infection. Analysis using RT-2600C and RT-2100C Microplate washer \& reader respectively was interpreted to subject serostatus according to the manufacturer's instruction (Rapid Labs Limited United Kingdom). All the controls and calibrators passed the validation test recommended by the manufacturer.

\section{Molecular Process :}

VIOGENE (VTR1-4-3) RNA extraction kit was used for the extraction process according to manufacturers manual. $A$ cDNA was achieved by the use of BIONEER cycle script RT premix $\left(\mathrm{dT}_{20}\right)$ for more stability and easier storage. The polymerase chain reaction was done with BIO-RAD peltier thermal cycler (PTC-100) and after gel preparation the resulting bands were read via BIO-RAD gel-2000 and compared with molecular weight markers of $1 \mathrm{~kb}$ DNA plus ladder of $0.9 u g /$ lane. 
The method of dye termination technique was employed using the quick start kit procedure according to Bechman coulter dye terminator cycle sequencing. and This involves the labeling of the chain terminator ddNTPs which permits sequencing in a single reaction rather than four reactions as in the labeled-primer method. Each of the four dideoxynucleotide chain terminator was labeled with fluorescent dyes emitting light at different wavelengths. The resulting sequence was subjected to live blast at National Center for Biotechnology Information (NCBI).

\section{Data entry and Analysis}

Results were compiled and analyzed via use of Statistical package for the Social Science (SPSS) version 17 software package at statistical significance level of $p<0.05$.

\section{Ethical consideration}

The ethical clearance was granted by the Federal Medical Center Ethical Review Committee. Informed consent was obtained from subjects after careful explanation of the study.

Table I : Rubella IgG \& IgM status in relation to history of rash among respondents

\begin{tabular}{|l|l|c|c|c|c|}
\hline \multicolumn{2}{|c|}{} & \multicolumn{2}{c|}{ HISTORY OF RASH } & Total & P values \\
\hline & & NO & YES & & \\
\hline RUBELLA Igm & NEGATIVE (\%) & $1(0.5)$ & $4(2.1)$ & $5(2.7)$ & 0.057 \\
\hline & POSITIVE (\%) & $118(63.1)$ & $61(32.6)$ & $179(95.7)$ & \\
\hline & EQUIVOCAL (\%) & $1(0.5)$ & $2(1.1)$ & $3(1.6)$ & \\
\hline & Total (\%) & $120(64.2)$ & $67(35.8)$ & $187(100.0)$ & \\
\hline & NEGATIVE (\%) & $116(63.7)$ & $63(34.6)$ & $179(98.4)$ & 0.446 \\
\hline & POSITIVE (\%) & $2(1.1)$ & $0(0.0)$ & $2(1.1)$ & \\
\hline & EQUIVOCAL (\%) & $1(0.5)$ & $0(0.0)$ & $1(0.5)$ & \\
\hline & Total (\%) & $119(65.4)$ & $63(34.6)$ & $182(100.0)$ & \\
\hline
\end{tabular}

$\mathrm{P}<0.05$ is significantly different: $\mathrm{X}^{2}-$ chi square " $(\operatorname{IgG})=5.722(\operatorname{IgM})=1.615$ "

Table II : Rubella IgG \& IgM status in relation to history of blood transfusion among subjects

\begin{tabular}{|l|l|c|c|c|c|}
\hline \multicolumn{2}{|l|}{} & \multicolumn{2}{c|}{ BLOOD TRANSFUSION } & Total (\%) & P values \\
\hline & & NO & YES & & \\
\hline RUBELLA IgG & NEGATIVE (\%) & $6(3.1)$ & $0(0.0)$ & $6(3.1)$ & 0.566 \\
\hline & POSITIVE (\%) & $165(84.6)$ & $21(10.8)$ & $186(95.4)$ & \\
\hline & EQUIVOCAL (\%) & $3(1.5)$ & $0(0.0)$ & $3(1.5)$ & \\
\hline & Total (\%) & $174(89.2)$ & $21(10.8)$ & $195(100.0)$ & \\
\hline RUBELLA IgM & NEGATIVE (\%) & $165(87.3)$ & $21(11.1)$ & $186(98.4)$ & 0.537 \\
\hline & POSITIVE (\%) & $3(1.6)$ & $0(0.0)$ & $3(1.6)$ & \\
\hline & Total (\%) & $168(88.9)$ & $21(11.1)$ & $189(100.0)$ & \\
\hline
\end{tabular}

$\mathrm{P}<0.05$ is significantly different: $\mathrm{X}^{2}$ - chi square " $(\mathrm{IgG})=1.139(\mathrm{IgM})=0.381$ "

Table III : Rubella IgG \& IgM status in relation to history of miscarriage among respondents

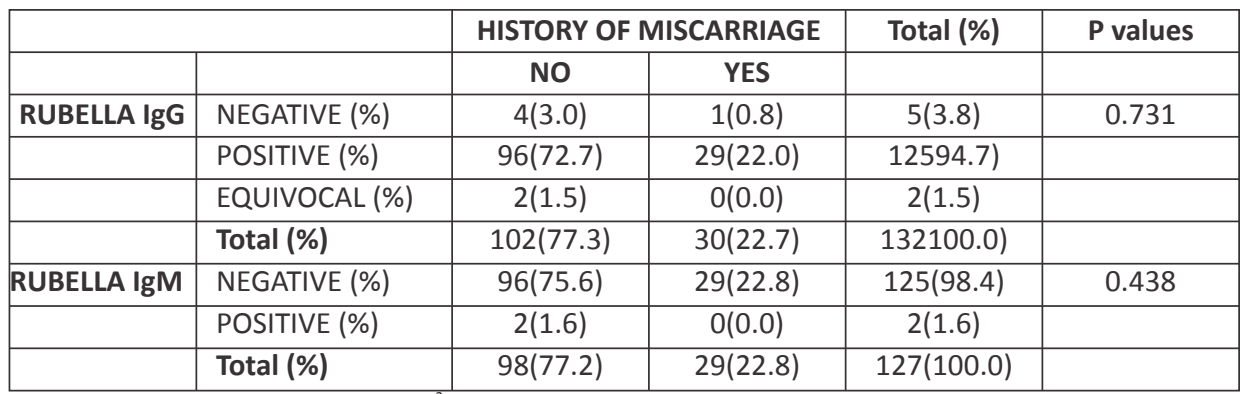

$\mathrm{P}<0.05$ is significantly different: $\mathrm{X}^{2}-$ chi square " $(\operatorname{IgG})=0.625(\operatorname{IgM})=0.601^{\prime \prime}$ 
Table IV: Rubella virus glycoprotein sequence

\begin{tabular}{|l|l|}
\hline Sequence result & Amplified product \\
\hline gcacggacaactcgaggtccaggtcccgcccgacccogggacctggttgagtacattatgaattaca & \\
ccggcaatcagcagtccogtggggctcgggagccoaattgccacggcccoattgggcctccccg & $320 \mathrm{bp}$ \\
gtttgccaacgccattccctgactgctcgcggcttgtgggggccacgccagagcgccccoggtgcgc & \\
ctggtcgacgccgacgacccctgctgcgcactgccctggaccoggcgaggtgtgggtcacgctgtc & \\
ataggctctcaggcgcgcaagtgcggactccacatacgcgctggac & \\
\hline
\end{tabular}

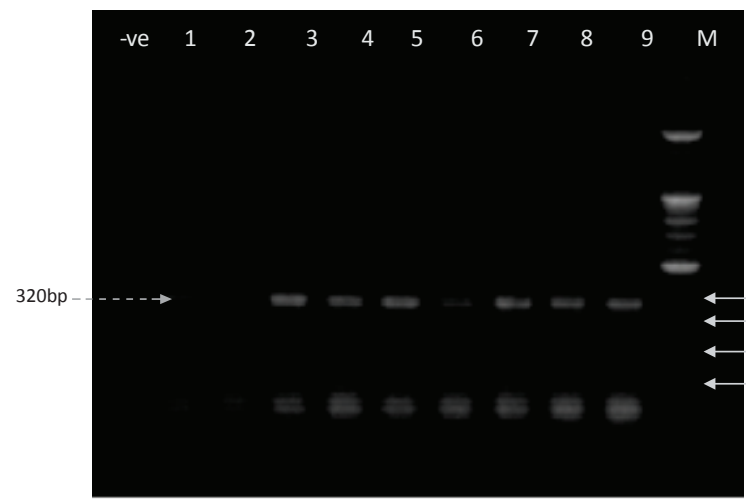

Plate 1: Rubella virus expression under UV transilluminator. (Expression of rubella virus protein on gel electrophoresis viewed under UV transilluminator. The bands shown are at 320bp on comparison with standard Molecular weight markers of $1 \mathrm{~kb}$ DNA plus ladder of $0.9 \mu \mathrm{g} / \mathrm{lane}$.)

-ve $=$ Negative control

$\mathrm{M}=$ Molecular weight marker

Lane 1-9= R1, R2, R3, R4, R5, R6, R7, R8, R9.

\section{Results :}

A total of 240 subjects were enrolled for this research and out of this consenting patient, only $6(2.50 \%)$ patients tested negative to Rubella IgG after assay (i.e. have not been exposed to the virus), 3 (1.25\%) were equivocal while the remaining 231 (96.25\%) IgG positive samples were assayed for Rub-IgM and 4 (1.7\%) subjects were positive. A $100 \%$. Cross tabulation of history of rash showed that $61(32.6 \%)$ from $67(35.8 \%)$ subjects that could recall history of rash were Rub-IgG positive while 118(63.1\%) from $120(64.2 \%)$ subjects that said otherwise were positive $(p=0.057)$ and rubella IgM samples were only recorded among subjects without history of rash ( $p=0.446)$ "Table l".

A $100 \%$ IgG positivity was recorded in the subjects that had history of blood transfusion i.e. 21(10.8\%) while those without had $165(84.6 \%)$ positivity. Three (3) subjects with no history of blood transfusion were IgM positive (Table II).

In Table III, 29(22.0\%) of 30(22.7\%) that has had miscarriage and $96(72.7 \%)$ out of $102(77.3 \%)$ without history of miscarriage were positive to rubella IgG $(P=0.731)$ while $2(1.6 \%)$ of $98(77.2 \%)$ without history of miscarriage were positive to rubella $\operatorname{lgM}(p=0.438)$.

Plate 1 expresses the molecular weight of rubella virus genome using Rub2\&7 and Rub8\&11 specific primers in subject serum. Rubella virus was detected in all the subjected samples which were previously positive to both/either IgG and IgM assay. The resulting bands are at $320 \mathrm{bp}$ after been compared with the standard at 100bp intervals. Sequence result after live blast confirmed an E1 membrane glycoprotein of Rubella virus of Togaviridae family (Rubella_E1).

\section{Discussion :}

Although most respondents couldn't recall any previous or current incidence of rash and "p- value" was statistically insignificant ( $p>0.05$ ), high seropositivity was recorded and this is not surprising since one of the features of the infection is passing unnoticed due to its symptom similarities to other infections in our locality such as the common cold. Asymptomatic carriers have also been reported in other studies ${ }^{9}$ and also in consistent with Obijimi et al., ${ }^{10}$ stating that only one subject could recall a history of rash with two subjects having a member of the family with rash and yet increased seropositivity was recorded. Pregnant women whose sera tested positive for rubella virus-specific IgM antibodies had no history of pregnancy loss. This is however not statistically significant $(p=0.438)$.

Another factor that was considered is blood transfusion because most blood transfusion doesn't require screening for rubella virus and with the high prevalence rate in our locality, transmission via blood can't be ruled out since body immunity in form of immunoglobulin $G$ persists throughout life time after initial exposure to the virus. Out 
of 195 subjects that responded to the question regarding blood transfusion, 186 (95.4\%) tested positive and among this, $21(10.8 \%)$ have had blood transfusion and all tested positive. It's logical to assume that other predisposing factors could be in play since route of blood transfusion may not have been directly pointed in the result but that doesn't rule out the fact that those subjects could have been infected via blood route. Further confirmation could be deduced from the rubella IgM result cross referenced with the history of blood transfusion where none of the subjects were positive implying that they were not undergoing a current infection and this is in line with the fact that their blood transfusion was also in the past. This corroborate to an earlier report by Junaid et al., ${ }^{12}$ however, it's not statistically significant $(p=0.381)$. $(p>0.05)$.

It's established that rubella virus infection could result in to loss of pregnancy in form of miscarriage or still birth. Of the total respondent to this, 30 of the 132 subjects have had miscarriage. The result from the cross reference of Rubella IgG status to miscarriage shows that 29 (96.7\%) out of the 30 had been exposed to rubella virus however, 1 (3.33\%) negativity to rubella IgG shows that all the miscarriage can't be linked to rubella viral infection since some other medical or non-medical factors could be involved to cause same effect. The remaining patients without history of miscarriage and yet tested positive to rubella IgG could be because they were not pregnant during the time of infection or the stage of the pregnancy might have passed the period were the virus can significant affect the fetus (pregnancy). Result from further test showed that all the women that have had a pregnancy loss were negative to current rubella infection (IgM) which could only mean that they had been exposed before and thus the positive result for IgG and not for IgM. It was also noticed that the 2 subjects that tested positive to rubella IgM had not experience any pregnancy loss before which might explain why they had no previous history of rash and this conforms to a report by Agbede et al., ${ }^{11}$ in UITH were the 3 pregnant women whose sera tested positive for rubella virus-specific IgM antibodies had no history of pregnancy loss. This is however not statistically significant $(p=0.438)$. " $p>0.05$ "
Question regarding blood transfusion, 186 (95.4\%) tested positive and among this, 21 (10.8\%) have had blood transfusion and all tested positive. It's logical to assume that other predisposing factors could be in play since route of blood transfusion may not have been directly pointed in the result but that doesn't rule out the fact that those subjects could have been infected via blood route. Further confirmation could be deduced from the rubella IgM result cross referenced with the history of blood transfusion where none of the subjects were positive implying that they were not undergoing a current infection and this is in line with the fact that their blood transfusion was also in the past. This corroborate to an earlier report by Junaid et al., ${ }^{12}$ but however, it's not statistically significant $(p=0.381)$. Molecular analysis of the subject sera under UV transilluminator confirms the presence of rubella virus genetic material (DNA) via its molecular weight shown at $320 \mathrm{bp}$ which is in range with other molecular study on rubella virus by Maria et al., ${ }^{13}$ on simultaneous detection of Measles virus, Rubella virus and parvovirus B19 were she had 320bp for rubella virus under UV transilluminator. Results from DNA sequencing of 320 letter product submitted to NCBI live blast search confirmed the rubella virus E1 membrane glycoprotein, a sole member in the genus Rubivirus of Togaviridae family. The virus consists of $40 S$ genomic RNA and a single species of capsid protein which is enveloped within a host-derived lipid bilayer containing two viral glycoproteins, E1 (58kDa) and E2 (42$46 \mathrm{kDa}$ ). Rubella virus matures and buds off from infected cells either at the plasma membrane or at the internal membranes depending on the cell type. It proceeds to enter adjacent uninfected cells by a membrane fusion process in the endosome and this is directed by E1-E2 heterodimers. The heterodimer formation is crucial for the transport of E1 out of the Endoplasmic reticulum to the Golgi and plasma membrane. This is in correlation with earlier reports ${ }^{14,15}$ from Conserved Domain Database (CDD) for the functional annotation of proteins.

The $\mathrm{E} 1$ has been shown to be a type 1 membrane protein that is rich in cysteine residues with extensive 
intramolecular disulfide bonds and has been implicated in the pathogenesis of the virus such as facilitating the fusion of viral envelope to endosomal membrane via conformational changes induced by $\mathrm{PH} 6.0^{16}$, studies by Hobman et al., ${ }^{17,18}$ reveals that it carries specific signals as heterodimer with $\mathrm{E} 2$ to direct the insertion of viral protein in to endoplasmic retriculum and further into golgi complex. The E1 transmembrane has also been revealed to play a critical role in the very late stage of virus budding in other research $^{19}$.

\section{Conclusion and Recommendation :}

Rubella_E1 membrane glycoprotein is a very important structural protein in the successful pathogenesis of rubella virus and detection of this glycoprotein in the subject serum is evident of the presence and continuous transmission of the virus. Also, it can be conclusively deduced that in addition to other established risk factors,

\section{References}

1. Geo FB, Janet SB, Stephen AM. 2004. Rubella. International edition, McGraw-Hill Companies, Asia 23: pp. 566-568.

2. Wolinsky JS, Knipe DM. 1996 Rubella in Fields 'Virology, ed. by Fields, Philadelphia, Lippen Cott-Raven; pp. 899-929.

3. Marchler-Bauer A and Bryant SH. 2004. Protein domain annotations on the fly; Nucleic acid resource. 32(w) 327-331.

4. Dominguez, G., Wang, C., Frey, T. (1990). Sequence of the genome RNA of rubella virus. Evidence for genetic rearrangement during togavirus evolution. Virology. 177(1); 225.

5. Yao, J., Yang, D., Chong, P., Hwang, D., Liang, Y. and Gillam, S. (1998) Proteolytic processing of rubella virus nonstructural proteins. Virology.246;74-82

6. Pugachev, K.V. and Frey, T.K. (1998). Rubella virus induces apoptosis in culture cells. Virology. 250;359-370.

7. Yang, D., Hwang, D., Qiu, Z. and Gillam, S. (1998). Effects in the mutation in the rubella virus E1 glycoproteins on E1-E2 interaction and membrane fusion activity. Journal of Virology. 72:8747-8755.

8. Araoye MO. 2004. Research methodology with statistics for health and social science. Sample size determination. Nathadex publishers: 118 21.

9. World Health Organization. Rubella vaccines. 2000. WHO position paper; Wkly Epidemiol Rec 75:161-975:161-9.

10. Obijimi TO, Ajetomobi AB, Sule WF, Oluwayelu DO. 2013. Prevalence of rubella virus-specific immunoglobulin-g and - $m$ in pregnant women attending two tertiary hospitals in Southwestern Nigeria. Afr. J. Cln Exper. Microbiol 14(3): 134-139.

11. Agbede OO, Adeyemi OO, Olatinwo AWO, Salisu TJ, Kolawole OM 2011. Sero-Prevalence of Antenatal Rubella in UITH. The Open Public Health Journal 4:10-16.

12. Junaid, S.A., Akpan, K.J. and Olabode, A.O. (2011). Sero-survey of rubella IgM antibodies among children in Jos, Nigeria. Virology Journal. $8 ; 244$ blood transfusion is another important route of rubella virus transmission that requires attention via screening before transfusion.

It is most appropriate for the Nigerian government to add Rubella vaccination to her immunization policy to cull the virus once and for all like other countries. It is not of strange occurrence were viruses becomes more virulent and resistant due to mutation caused by different host immunity reactions to the invading antigen and its continuous localized transmission.

\section{Aknowlegdement :}

We appreciate Mr and Mrs Suleiman, Dr Stephen Ogah, Mrs Grace Itodo, all the consenting patients for their cooperation and understanding and also the staffs of DNA labs Kaduna and Federal Medical Centre ( $O$ and G section and ethical board) Lokoja.

13. María del MM., Fernando de O, Mónica M, Juan, E. 2002. Simultaneous Detection of Measles Virus, Rubella Virus, and Parvovirus B19 by Using Multiplex PCR. Journal of clinical microbiology. 40(1); 111-116.

14. Marchler-Bauer A, Lu S, Anderson JB, Chitsaz F, Derbyshire MK, DeWeese-Scott C, Fong JH, Geer LY, Geer RC, Gonzales NR, Gwadz M, Hurwitz DI, Jackson JD, Ke Z, Lanczycki CJ, Lu F, Marchler GH, Mullokandov M, Omelchenko MV, Robertson CL, Song JS, Thanki N, Yamashita RA, Zhang D, Zheng C, Bryant SH. 2004. Nucleic Acid Resources. E-public medicine; d205-10.

15. Marchler-Bauer A, Lu S, Anderson JB, Chitsaz F, Derbyshire MK DeWeese-Scott C, Fong JH, Geer LY, Geer RC, Gonzales NR, Gwadz M, Hurwitz DI, Jackson JD, Ke Z, Lanczycki CJ, Lu F, Marchler GH, Mullokandov M, Omelchenko MV, Robertson CL, Song JS, Thanki N, Yamashita RA, Zhang D, Zheng C, Bryant SH. 2009. Nucleic Acid Resources. E-public medicine; d205-10.

16. Petruzziello R., Orsi N., Macchia S., Rieti S., Frey T, Mastromarino P. 1996. Pathway of rubella virus infectious entry into Vero cells. J. Gen. Virol. 77:303-308.

17. Hobman, T.C. and Gillam, S. (1989). In vitro and in vivo expression of rubella virus glycoprotein E2: the signal peptide is contained in the $C$ terminal region of capsid protein. Virology. 173; 241-250.

18. Hobman, T., Chantler, J., Knipe, D.M., Howley, P.M., Griffin, D.E., Martin, M.A., Lamb, R.A., Roizman, B. and Straus, S.E. (2007). Rubella Virus. Virology, 5thed. PA, USA: Lippincott Williams \& Wilkins; 10691100

19. Garbutt, M., Law, M. J., Chan, H. and Hobman, T. C. (1999). Role of rubella virus glycoprotein domains in assembly of virus-like particles. Journal of Virology. 73; 3524-3533. 